\title{
OPINION \\ Should HIV be a notifiable disease? Old questions with some new arguments
}

\author{
W D F Venter, A Black, L Allais, M Richter \\ Francois Venter is an HIV clinician in the Wits Reproductive Health and HIV Institute (RHI), Johannesburg, South Africa, and an associate \\ professor in the School of Clinical Medicine, Faculty of Health Sciences, University of the Witwatersrand, Johannesburg. He is interested in improving \\ public sector health. Andrew Black is a pulmonologist at the RHI with an interest in infectious diseases. Lucy Allais is Professor of Philosophy and \\ Director, Wits Centre for Ethics, at the University of the Witwatersrand and a senior lecturer at the University of Sussex in the UK. She works on \\ a variety of topics in ethics and bioethics. Marlise Richter, of Sonke Gender Justice and visiting researcher at the African Centre for Migration and \\ Society, University of the Witwatersrand, and the School of Public Health and Family Medicine, University of Cape Town, South Africa, works on \\ issues of gender-based violence, with a specific focus on sex workers.
}

Corresponding author: W D F Venter (fventer@wrhi.ac.za)

HIV notification enters national debate regularly, often introduced by politicians and supported by many individual healthcare workers. We argue that its proponents advance confused or poorly informed rationales for making HIV notifiable. We present reasons why making HIV notifiable would be inappropriate in South Africa, why the public health benefits of a notification programme are not even likely, and why there are risks of public health and human rights harms.

S Afr Med J 2014;104(9):607-609. DOI:10.7196/SAMJ.8468



Should HIV be notifiable in South Africa (SA)? When this question was first discussed, decades before widespread access to antiretroviral therapy (ART), the answer was a resounding 'no. ${ }^{[1-3]}$ As we outline below, medical staff, politicians and the public have continued to ask the question about HIV notification since then, but the debate lost traction in SA at the turn of the century. However, during the June 2012 African National Congress (ANC) policy conference, the party expressed support for a notification policy for $\mathrm{HIV},{ }^{[4]}$ which has refocused attention on the debate for the first time in over a decade. ${ }^{[5,6]}$

\section{The history of the HIV notification debate in SA}

HIV is reportable in many developed and developing countries. ${ }^{[7]}$ The SA HIV landscape has changed enormously in the last few years, including the provision of broad-based HIV testing ensuring that over half the nation knows their status, with free access to $\mathrm{ART}^{[8]}$ In the context of increasing argument that HIV should be de-exceptionalised, it might be thought that established public health measures should once again be considered. Yet there has been no formal discussion on notification in the new era of widespread HIV testing and antiretroviral access. Do the changes in the HIV epidemic in SA justify reopening the debate and a new call for HIV notification, as we see from the ANC policy conference? We argue that they do not.

In 1988, when fewer than 100 people with HIV had been identified in SA, the question of notification was discussed in the SAMJ by prominent medical scientists, who recommended 'detailed study and discussion and consultation with the groups at risk' before a notification decision was made. ${ }^{[3]}$ At the time testing for HIV was not routine; clinically defined AIDS usually triggered confirmatory HIV testing. This is in stark contrast to the current situation, where access to HIV testing is widespread and effective therapy is freely available.
In the 1980s and 1990s, notification was seen by some as an antidote to secrecy and a necessary step to deal with HIV pragmatically. ${ }^{[9,10]}$ At the time, the Minister of Health, Nkosazana Dlamini Zuma, strongly advocated the notification of HIV: 'We can't afford to be dictated to by human rights or AIDS activists. We want to know who is dying of AIDS, and relatives and partners must be notified. It is time we treated AIDS as a public health issue like TB. We don't go about treating that with secrecy. ${ }^{[11]}$ In a response to human rights violations and stigma surrounding people living with HIV/AIDS, human rights advocates strongly resisted this classic public health approach to the epidemic. They emphasised the need for an individual's confidentiality and argued that there was little personal or public health benefit to making HIV notifiable. ${ }^{[12]}$ HIV notification continued to be repeatedly raised by health officials and politicians (by Dlamini Zuma in 1997, against the advice of the Department of Health's own National STD/HIV/ AIDS Review and National AIDS Advisory Committee, by the New National Party and the Inkatha Freedom Party, and most recently at the 2012 ANC policy conference), ${ }^{[2,4.6,13-15]}$ often linked to a demand for quarantine. ${ }^{[16,17]}$ The SA government prepared draft guidelines for reporting HIV in 1999, but never passed them. Concerns at the time were comprehensively discussed in the legal literature. ${ }^{[6,12,16]}$

\section{Justification for disease notification}

What is notification? The SA disease notification system mirrors policies in many other countries, where 'notification' is a legal obligation on the part of healthcare workers to report to public health authorities, by patient name (and in some states in the USA by a patient number) an identified specific disease (usually an infectious disease) that is thought to have implications for the public. In SA, a specific case report form needs to be submitted within 24 hours for certain categories of infection (e.g. rabies, polio, cholera), and within 7 days for other conditions (e.g. tuberculosis (TB), hepatitis B). ${ }^{[18]}$

Traditionally, the justification for a notification system is to alert authorities about diseases that require immediate public 
health intervention, for evaluation of changing disease patterns and identification of communities that require special responses. The SA Department of Health's official justification for notification is similar, with the wording 'to plan and implement health promotional and intervention strategies. ${ }^{[19]}$ With illnesses such as cholera and polio, early warning can lead to immediate interventions that can protect populations (cutting off a contaminated water source for cholera, vaccine mop-ups in polio). This area of public health has attracted little controversy among medical ethicists or human rights groups, other than raising concerns about possible breaches of confidentiality. ${ }^{[20]}$ However, in other respects notification has come into conflict with human rights protagonists, for example over the forced testing for venereal disease in Britain and the USA over 100 years ago. ${ }^{[21,22]}$ Although in theory legal sanction is available if healthcare workers do not comply, no health professional has recently been investigated, let alone sanctioned. (Multiple attempts by the authors over 18 months to get this information from the Health Professions Council of South Africa (HPCSA) were only successful after the direct intervention by the HPCSA ombudsman.)

\section{What are the arguments for HIV notification?}

HIV is contagious, preventable and treatable, making action-orientated public health interventions appealing. ART for those who are infected has revolutionised the disease, with a near-normal life expectancy with good adherence. ${ }^{[23]}$ Added to this has been the finding that effective ART can completely arrest transmission. ${ }^{[2]}$ As with other HIV debates about 'disclosure', the issue of HIV notification is often regarded as pitting human rights against public health. ${ }^{[25]}$ Here, however, we focus on the question of whether notification is a useful public health measure.

Traditional reasons for making a disease 'notifiable' are:

- Diseases that may require immediate public health intervention and follow-up. This implies urgency and action in the midst of rapidly evolving disease epidemiology. However, the HIV epidemic is stable and well documented, with well-established prevention and treatment programmes, and excellent research in the fields of both behaviour and uptake of prevention interventions. Notification would not add any additionally useful information.

- Evaluation of changing disease patterns. SA has some of the most sophisticated HIV statistics in the world, in an epidemic that has been well documented since the early 1990s, through the government's antenatal surveys, Statistics South Africa's analysis of death certificates, and the Human Sciences Research Council's regular household surveys. ${ }^{[8,26,27]}$ It is unlikely that notification, as discussed below, could match the rigour of these ongoing projects. Finally, HIV is asymptomatic for years and even decades. Notification would probably find only the sick, or when someone tests voluntarily, which is a poor way to understand changing transmission patterns.

- Identification of communities that may require special responses. Vulnerable groups that require special responses have already been identified as so-called 'key populations' in SA's current AIDS policy, with tailored HIV treatment and prevention responses. ${ }^{[28]}$ Acute $\mathrm{HIV}$, which is very infectious, is very rarely identified using current testing strategies, so using notification as a means of 'outbreak control' is not feasible. This means that even if an outbreak occurs in a specific community, it seems unlikely that it will be recognised rapidly. More conventional active research and surveillance would be a better mechanism to identify outbreaks.
'HIV-specific' reasons advanced are:

- Notification will give us more accurate statistics. This is often quoted as justification for HIV notification, including by a previous Minister of Health. ${ }^{[2]}$ In one Indian state, it is advanced as the sole reason - to obtain better data. ${ }^{[29]}$ As discussed, SA has very robust HIV statistics. Proponents are also usually unaware that notification data are notoriously badly collected, with severe under-reporting documented for many diseases. . $^{[1,22,30,31]}$

- Notification will allow us to warn sex partners at risk of contracting HIV. Suppose citizen X tests positive, an investigative team is deployed to provide advice and support, and a letter is sent or a phone call made to tell their partner that he or she may be at risk of contracting, or have contracted, HIV. In addition to concerns over confidentiality, the negative consequences of such a practice are obvious: once it becomes known that testing will lead to some form of forced disclosure, patients will simply either not come forward for testing, or stop reporting who their sex partners are. The resources required to investigate, inform and verify every newly diagnosed case of HIV in SA each year would be prohibitive, even if we only limited it to current sexual partners. Follow-up and the continued warning of new partners for all patients not on ART or with detectable viral loads would also be required. The poor state of TB contact tracing, a far less ambitious project, demonstrates the practical challenges inherent in such a system. Finally, notification is not needed to warn sexual partners, as there is clear guidance from the HPCSA's Ethical Guidelines for Good Practice with Regard to $H I V$ on disclosure of HIV status to a third party. These set out the narrowly prescribed conditions under which a healthcare worker may have a duty to warn sexual partners, and the procedures for doing so against a patient's wishes. ${ }^{[32]}$

- Notification would allow us to isolate people with HIV. This argument occasionally surfaces, often with reference to a romanticised version of Cuba's HIV policy that involved quarantine of people with HIV. ${ }^{[33,34]}$ It appeals to an authoritarian public health streak that is seen in many discussions on provision of preventive healthcare. The ethical and human rights arguments against it are compelling and straightforward. HIV-negative people's rights are not removed in a consensual sex environment. As well as being hugely impractical, trying to protect HIV-negative people who can in fact take actions to protect themselves by somehow isolating the $15 \%$ HIV-positive section of the population (the equivalent of the entire population of Mpumalanga and Limpopo combined) would infringe fundamental human rights without any possible proportionate justification. Sex is largely a voluntary act between consenting adults, and risk reduction is possible through the use of condoms or other safe sex practices. Non-disclosure of HIVpositive status is covered by current legal frameworks, allowing prosecution in most legal systems, so notification is not needed for this reason. It is interesting to note that since the lifting of its incarceration policy many years ago, Cuba has not witnessed a dramatically increased HIV rate. A second area that poses more debate is the issue of quarantine of seroconverters, at which stage HIV is hyperinfectious. However, we do not have any evidence of reckless behaviour after a positive diagnosis, and simple counselling has been found to be effective in certain US states, where acute seroconversion patients are identified and contacted and prevention counselling initiated. ${ }^{[35]}$ Even in more dangerous and widely communicable diseases, such as multidrug-resistant TB, incarceration is controversial. ${ }^{[17]}$ Punitive measures for HIV seroconverters are unnecessary, draconian, and inconsistent with human rights. 
Critics of notification argue that it could increase stigma. However, the data to support this claim from countries that have implemented notification systems does not appear to be any more than anecdotal, and even if it were true, it might not provide sufficient reason by itself not to have a notification system, if the public health benefits were substantial. Critics have also raised fears about violation of confidentiality, but again there do not appear to be reported data to back this up. Even if cases did occur, sanctions are available against healthcare staff, as with all health confidentiality issues. In many countries or states, notification systems have been implemented with little reported evidence of such problems. However, SA has many examples of people being discriminated against, fired and even murdered on disclosing their HIV status in communities, so care is required, as legal channels cannot offer absolute protection. ${ }^{[6]}$ Confidentiality is a fundamental ethical tenet of medical practice, and should not be casually dispensed with, especially when social harms on HIV forced disclosure are well documented.

Given the effectiveness of interventions to prevent mother-tochild transmission (PMTCT) of HIV, it could be argued that HIVinfected infants may be a unique group where notification could lead to immediate investigation. Notification could fulfil a role in alerting health authorities of breakdowns in prevention systems, much like reports of vaccination-preventable diseases such as measles, or water contamination in the case of cholera. The current monitoring systems for PMTCT are sufficiently robust to detect system failures, but they lack the rapid investigation and response component that notification would allow for. However, the notification of HIVinfected infants may have negative consequences such as pregnant women refusing antenatal testing of themselves or postnatal testing of their babies. This would decrease the uptake of PMTCT interventions and treatment of HIV-infected infants, and worsen rather than improve the PMTCT programme. Finally, there are a large number of other 'system failure' markers that are not notifiable, including drug stock-outs, needlestick injuries, antibiotic resistance, and even health staffing levels. It seems peculiar and ineffective to focus only on PMTCT.

We are not arguing that notification has no role in other diseases. We think there is a compelling public health reason for urgent notification of illnesses such as polio and cholera, even where confidentiality is compromised, although we believe that compromise should and could easily be minimised by restricting this information to health officials. However, several of our arguments could apply to other diseases that are currently deemed 'notifiable' in SA, and we believe that a debate on why and how notification occurs and a review of the current notifiable diseases list is overdue.

\section{Conclusion}

Notification broadly can sometimes be a valuable adjunct to public health, but not in the generalised HIV epidemic in SA. Collectively, proponents of notification overstate the need for accurate statistics and the range of practical interventions available to act on successful HIV notification, underplay the possible harm of forced disclosure in communities, and are too cavalier about violating confidentiality. Notification is not necessary for proper planning or provision of treatment, notification of sex partners is unenforceable, there are currently good guidelines to deal with patients unwilling to disclose their status to sex partners, and better HIV statistics are available elsewhere. There are substantive disadvantages, including creation of yet further bureaucracy and allied cost, inadvertent disclosure of HIV status in communities where this is dangerous, and the possibility of driving the disease underground, after several years of human rights and health gains, undermining gains in getting people tested and on treatment. Notification with attached legal sanctions on sexual behaviour would fundamentally affect the freedoms of a large segment of the population, and, as with most legislation on consensual sex, would be unenforceable and simply contribute to stigma and undermine autonomy.

In 2014, we need to let this debate go. Setting up the notification debate as one of public health versus human rights is misguided. It is quite easy, in the case of HIV notification, to respect both.

Acknowledgements. Prof. Moosa Patel, Division of Clinical Haematology, Department of Medicine, Chris Hani Baragwanath Academic Hospital and University of the Witwatersrand, asked the question. Dr Black and Prof. Venter are funded by the US President's Emergency Plan for AIDS Relief (PEPFAR).

1. Abdool Karim SS, Abdool Karim Q. Under-reporting in hepatitis B notifications. S Afr Med J 1991;79(5):242 Colvin M. Should AIDS be notifiable? S Afr Med J 1999;89(2):147-148

Ijsselmuiden CB, Steinberg MH, Padayachee GN, et al. AIDS and South Africa - towards a comprehensive strategy: Part I. The world-wide experience. S Afr Med J 1988;73(8):455-46

Mataboge M, du Plessis C. ANC wants new Constitution. City Press, 3 March 2012. http://www.citypress.co.za/ news/anc-wants-new-constitution-20120303-2/ (accessed 15 May 2014)

Daniels A. Aids should become a notifiable disease, readers. IOL News, 25 May 2009. http://wwwiol.co.za/ May 2014)

6. AIDS Law Project. Submission on regulations relating to communicable diseases and the notification of notifiable medical conditions. 1999. http://www.section27.org.za/wp-content/uploads/2010/04/RegulationRelating-to-Communicable-Diseases-1999-ALP.pdf (accessed 15 May 2014).

7. Wikipedia. List of notifiable diseases. 2014. http:///en.wikipedia.org/wiki/List_of_notifiable_diseases (accessed 15 May 2014)

8. Shisana O, Simbayi LC, Zuma K, Jooste S, Zungu N, Labadarios D. South African National HIV Prevalence, Incidence and Behaviour Survey, 2012. Cape Town: HSRC Press, 2014.

Vlaminckx BJ, Boucher CA. [HIV should become a notifiable disease]. Ned Tijdschr Geneeskd 2007;151(48):2672. Mae P. Medical confidentiality and the public disclosure of HIV status. Journal of South Pacific Law 2004;8(1).

1. Cherry M. South Africa reveals plans to make AIDS a notifiable disease. Nature 1999;399(6734):288. [http./1

12. South African Law Reform Commission. Aspects of the Law Relating to AIDS (Project 85). Pretoria: South African Law Reform Commission, 1997.

. Helen Suzman Foundation. Aids notification 1999. http://www.hsf.org.za/resource-centre/focus/issues-11-20/ issue-15-third-quarter-1999/aids-notification (accessed 2 August 2014).

14. Taitz L. Zuma makes doctors report AIDS patients. Sunday Times 1999. http://wwl.aegis.org/news/

suntimes/1999/ST990402.html (accessed 15 May 2014).
15. Sidley P. South Africa plans to make AIDS a notifiable disease. BMJ 1999;318(7194):1308. Epub 1999/05/14. [http://dx doiorg/10.1136/bmi318.7194.1308]

16. Cameron E. Legal and human rights responses to the HIV/AIDS epidemic in South Africa. Stellenbosch Law Review 2006;1(17):47-90.

17. Carstens $\mathrm{P}$. The involuntary detention and isolation of patients infected with extreme resistant tuberculosis XDR-TB): Implications for public health, human rights and informed consent: Case. Obiter 2009;30(1):420-

18. Department of Health. Public health surveillance system. Epidemiological Comments 2011;2(1). http:// www.doh.gov.za/docs/reports/2012/epicomments2.pdf (accessed July 2013; document no longer available at

9. Debsite).

(accessed July 2013; document no longer available at website). (accessed 15 May 2014)

notifiable-disease/ (accessed 15 May 2014). org/Publications/IRC-pub01/jc338-name-based_en.pdf (accessed 15 May 2014).

23. Miller V, Hodder S. Beneficial impact of antiretroviral therapy on non-AIDS mortality. AIDS 2014;28(2):273274. [http://dx.doi.org/10.1097/QAD.0000000000000079]

4. Cohen MS, Chen YQ, McCauley M, et al. Prevention of HIV-1 infection with early antiretroviral therapy. N Engl I Med 2011;365(6):493-505. [http://dx.doi.org/10.1056/NEJMoal105243]

25. Pieterse M. The interdependence of rights to health and autonomy in South Africa. S Afr Law I 2008;:125(3):553-572.

Afrool Karim SS, Churchyard GJ, Abdool Karim Q, Lawn SD. HIV infection and tuberculosis in South 列 need to escalate the public health response. Lancet 2009:374(9693):921-933. [http://dx doi. org/10.1016/S0140-6736(09)60916-8] 7. Rehle TM, Hallett TB, Shisana O, et al. A decline in new HIV infections in South Africa: Estimating HIV
incidence from three national HIV surveys in 2002, 2005 and 2008. PLoS One 2010;5(6):el 1094. [http://dx.doi.

org/10.1371/journal.pone.0011094]
28. South African Department of Health. The National Strategic Plan on HIV, STIs and TB 2012-2016. http:// www.sahivsoc.org/upload/documents/National_Strategic_Plan_2012.pdf (accessed 15 May 2014).

Tha S. Aids/HIV to be a notifiable disease in Biha. Times of India 2002; 9 November. http://timesofindia. ndiatimes.com/city/patna/Aids/HIV-to-be-a-notifiable-disease-in-Bihar/articleshow/27706909.cms

3. Weber I. Evaluation of the notifiable disease surveillance system in Gauteng Province, South Africa. University of Pretoria, 2007. http://upetd.up.ac.za/thesis/available/etd-07302008-141155/unrestricted/dissertation.pdf Abdool Karim SS, Dilraj A. Reasons for under-reporting of notifiable conditions. S Afr Med J 1996;86(7):834836.

32. Health Professions Council of South Africa. Ethical Guidelines for Good Practice with regard to HIV. Pretoria: HPCSA, 2007. http://wwwhpcsa.co.za/Uploads/editor/UserFiles/downloads/conduct_ethics/rules/generic_

33. Hoffiman SZ. HIV/AIDS in Cuba: A model for care or an ethical dilemma? Afr Health Sci 2004;4(3):208-209. 4. Anderson T. HIV/AIDS in Cuba: Lessons and challenges. Rev Panam Salud Publica 2009;26(1):78-86. [http:// dx.doi.org/10.1590/S1020-49892009000700012

Dection of acute infections during HIV testing in North Carolin Thed 2005:352(18):1873-1883. [http://dx.doi.org/10.1056/NEJMoa042291]

Accepted 20 June 2014. 